\title{
Information Literacy in Science and Engineering Undergraduate Education: Faculty Attitudes and Pedagogical Practices
}

\section{Gloria J. Leckie and Anne Fullerton}

\begin{abstract}
What are science and engineering faculty doing with respect to the development of information literacy in their undergraduate students? To explore this question, science and engineering faculty at two large Canadian universities were surveyed and interviewed regarding their perceptions of their students' information literacy skills and their own pedagogical practices related to such skills. Faculty awareness of, and support for, a variety of bibliographic instruction methods and the perceived role of science and engineering librarians in information literacy instruction also were investigated. Based on the survey results, suggestions for the design of library instruction for science and engineering undergraduates are made.
\end{abstract}

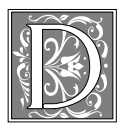

espite the argument that technological advances have made access to information easier, there is an ongoing concern that university students still are not becoming information literate, that they cannot retrieve and evaluate the information that will be required for problem-solving and decision-making in the workplace and in society generally. Evidence is rapidly mounting that students cannot select appropriate sources of information, do not understand the structure or purpose of different sources of information, and cannot critically evaluate the information they retrieve. ${ }^{1}$ These concerns are even more pressing now than in the past because the amount of information that students can access rapidly and easily is growing exponentially, yet at the same time, studies have shown that students have great difficulty using even a small proportion of the citations they retrieve.

Solid information literacy skills are desirable across all disciplines, including science and engineering, a fact that is not entirely lost on the professional associations. A reader response poll in the journal Chemical Engineering Progress revealed that chemical engineers today spend a considerable amount of time retrieving and using information on a wide variety of topics, including management, regulatory requirements, economic forecasts, and research methodologies. ${ }^{2}$ However, despite the need for such diverse kinds of information, the survey also found that the respondents depended on personal

Gloria J. Leckie is Associate Professor of Faculty of Information and Media Studies at the University of Western Ontario; e-mail: leckie@julian.uwo.ca. Anne Fullerton is a Librarian for Biology and Chemical Engineering in Davis Centre Library at the University of Waterloo; e-mail: affuller@library.uwaterloo.ca. 
collections and other engineers for their information, and were not making good use of the growing number of electronic options. More than half the survey respondents attributed this to their inability to find and use appropriate information. Studies of the information-seeking behavior of scientists across a variety of disciplines suggest there are similarities. Geoscientists, for instance, find the burgeoning literature of their fields to be problematic and so rely on personal contacts as the primary means of identifying relevant information, thus overlooking other important sources. ${ }^{3}$

... it is quite possible for science and engineering undergraduates to avoid the library, if not completely, at least until relatively late in their educational experience.

Where will future working scientists and engineers develop the fundamental information literacy skills they will need on the job? Should a university education include the development of strong information literacy skills in students? If so, who is responsible for ensuring the development of such skills? What factors are involved in whether or not this happens? For many academic librarians, the question is not whether there should be information literacy/bibliographic instruction (BI) but, rather, how best to provide it. ${ }^{4}$ Current thinking on this reflects adult learning theory, acknowledging that BI will be more effective if it is course related and delivered at the time of need (e.g., when an assignment or essay is due). Along with this, there has been a longstanding recognition that the support of the teaching faculty for a BI program is critical.

However, the issue of faculty support immediately raises a number of troubling questions. Do faculty truly support the BI efforts made by academic librarians? Do they have an appreciation of the concepts that must be instilled? Are they satisfied with the library research capabilities of their students? Are they aware of how academic librarians could work with them to develop information literacy and critical thinking skills in their students? What factors affect their support for BIdiscipline, level of teaching, their own information-seeking habits?

As J. Edmund Maynard has pointed out, faculty attitudes toward BI are highly variable and inconsistent. ${ }^{5}$ According to a major study by Larry Hardesty, this inconsistency arises partly because faculty themselves often have a poor grasp of the role and complexity of the contemporary university library. ${ }^{6} \mathrm{He}$ found that science faculty in his study generally held the library in lower esteem than did faculty in the other two areas. ${ }^{7}$ This is compounded by the fact that use of the library by science faculty in their own research also may be less frequent than in the social sciences and humanities. Thus, it may be that the incorporation of information literacy into science and engineering education is linked to the attitudes and practices of the faculty, many of whom have been found to be more indifferent to the role of the library in undergraduate education than their colleagues in the social sciences and humanities.

Hardesty and many others suggest that academic librarians can make a crucial difference in ensuring that information literacy skills are integrated into the student's program in some manner and must make significant efforts to work with faculty. However, this is not an easy task, and numerous studies have shown that librarians and faculty do not understand each other's role or expectations very well. ${ }^{8}$ This lack of communication has implications for the work of both librarians and faculty in meeting the mission of their institution. Although both groups want to ensure that students are receiving a high-quality education and have the necessary skills for lifelong learning, on many campuses there is considerable confusion about who is responsible for teaching information literacy skills. This frequently results in duplicated or misdirected efforts in teaching information literacy skills to particular 
types of students, ultimately costing the institution in terms of the allocation of human and fiscal resources.

With these reasons in mind, Anita Cannon conducted a study of faculty perceptions at York University in Toronto, Ontario, in $1994 .{ }^{9}$ The study was conceived to explore faculty attitudes toward BI activities, gain a greater understanding of the library research instruction needs of students, and determine what approaches to meeting those needs would be most supported by faculty. A twentyitem questionnaire was sent to all fulltime faculty members in the social sciences and humanities (565 individuals), with 229 responding.

Cannon found that the majority of faculty rated information literacy skills as being valuable or extremely valuable for their students. Generally, they thought that lower-level undergraduates had poor information literacy skills but that this improved in the upper years. Although many faculty had had a librarian come into their classes to discuss library research, most had not, and a large number were unaware that librarians would do this. Support was greatest for BI in using computerized information resources for both students and the faculty themselves. However, there were noticeable differences by discipline in terms of faculty awareness and pedagogical practices. Cannon also found, somewhat surprisingly, that the majority of faculty who responded favored a shared approach to teaching information-related skills.

Although Cannon's study is invaluable as a window into faculty perceptions of BI, the patterns of teaching and research in the humanities and social sciences do not necessarily hold true for the sciences and engineering. The ways in which the knowledge base of the latter disciplines is imparted may have an impact on the development of information literacy in students. For instance, Janice Kelland has noted that in physics, the reliance on deriving equations and conducting experiments may account for the conspicuous absence of any references to the need for students in that field to have library-based research skills. ${ }^{10}$ As well, in engineering and the other sciences, students may primarily use standard texts for as long as the first two or three years of study, and thus do not begin to develop information retrieval skills until their senior year, or even graduate school. In other words, it is quite possible for science and engineering undergraduates to avoid the library, if not completely, at least until relatively late in their educational experience. Despite fears that science and engineering students do not have the requisite information literacy skills upon graduation, there is still a very limited understanding of when and how such skills should be incorporated into the curricula of the different disciplines across the sciences and engineering. Furthermore, very little research has investigated the attitudes/ perceptions of science and engineering faculty with respect to this issue.

\section{Objectives}

In light of the above, the present study was designed to enhance our understanding of cross-disciplinary needs for bibliographic instruction by investigating faculty perceptions of, attitudes toward, and pedagogical practices in teaching information literacy in the sciences, health sciences, and engineering. ${ }^{11}$ This goal is in line with Cannon's recommendations that further research is needed to explore the differences in faculty support for BI activities across a variety of disciplines. ${ }^{12}$

The research was conducted in two parts. Part one involved a replication (with some modification) of Cannon's survey, but with science and engineering faculty. The replication is important because it establishes a relatively large and consistent data set from three major universities. Because these universities are very similar with respect to their overall culture, makeup of the faculty and student body, and library resources, the results are highly comparable, enabling the authors of this study to draw together findings from the arts/humanities, social sciences, sciences, and engineering. 


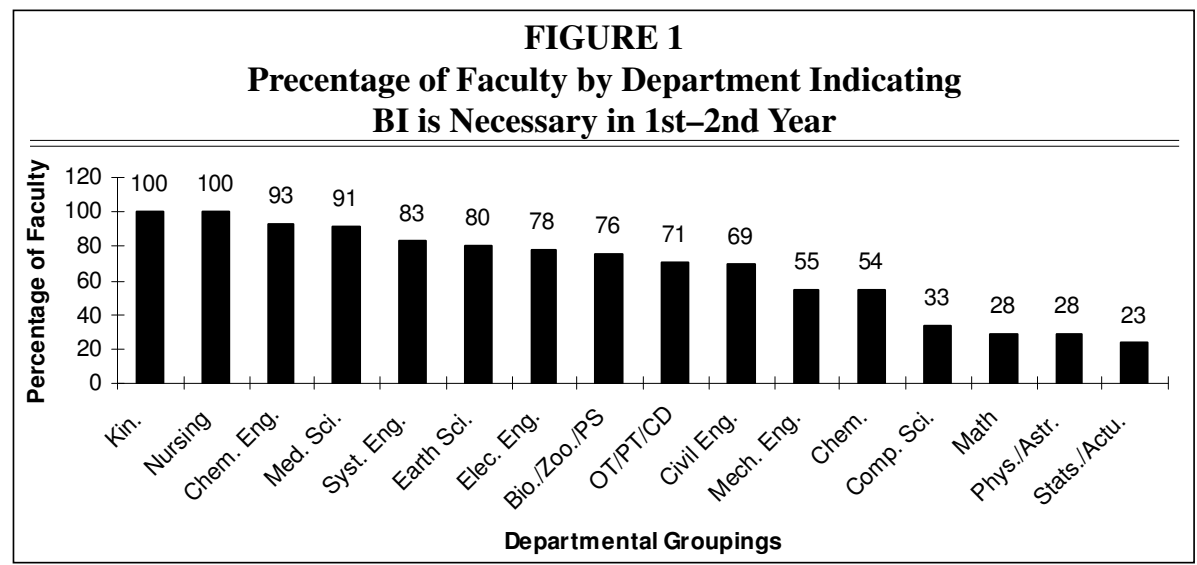

Part one had the following specific objectives:

1. to determine how science and engineering faculty assess the information literacy skills of their students;

2. to explore the various practices employed by faculty to develop information literacy in their students;

3. to solicit faculty perceptions of the role of science and engineering librarians in providing bibliographic instruction;

4. to determine levels of faculty support for various bibliographic instruction options;

5. to discover patterns in faculty awareness of, and support for, bibliographic instruction by discipline and by department.

Although Cannon's survey instrument facilitates the collection of certain basic data, it does have a number of shortcomings. For instance, although her data revealed that library-based assignments were the most popular pedagogical practice by faculty, the survey was not designed to elicit detailed information about the types of assignments that faculty give their students, nor their expectations about what the students should demonstrate in such assignments. Therefore, the objective of part two of the research was to provide the investigators with a more complete picture of the expectations and practices of science and engineering faculty with respect to BI through in-depth interviews with a smaller sample of faculty. Thus, part two of the study extends
Cannon's original research and permits exploration of potential explanations of results obtained through the survey portion of the study.

\section{Methodology}

The study was conducted at two sites: the University of Waterloo (Waterloo, Ontario) and the University of Western Ontario (London, Ontario). These universities were chosen because both have rather large and diverse engineering and science faculties, thus giving access to an adequate sample of teaching faculty. Furthermore, the current practice of these library systems in providing bibliographic instruction to science and engineering students was already known to the investigators.

For part one, a revised version of Cannon's survey instrument was used as the means of data collection. After pretesting, a 28-item survey was sent in the fall of 1996 to all science and engineering faculty (including sessional, part-time, and full-time) at the two universities (400 at Waterloo and 434 at Western, totaling 834). Follow-up letters were sent two weeks after the initial mailing. In addition to the survey, which was returned anonymously, a statement-of-interest card was included in the package, to be returned separately by those faculty members who would agree to a personal interview. The response rate for the survey was 28 percent (233), slightly lower than expected, but a reasonable response for 


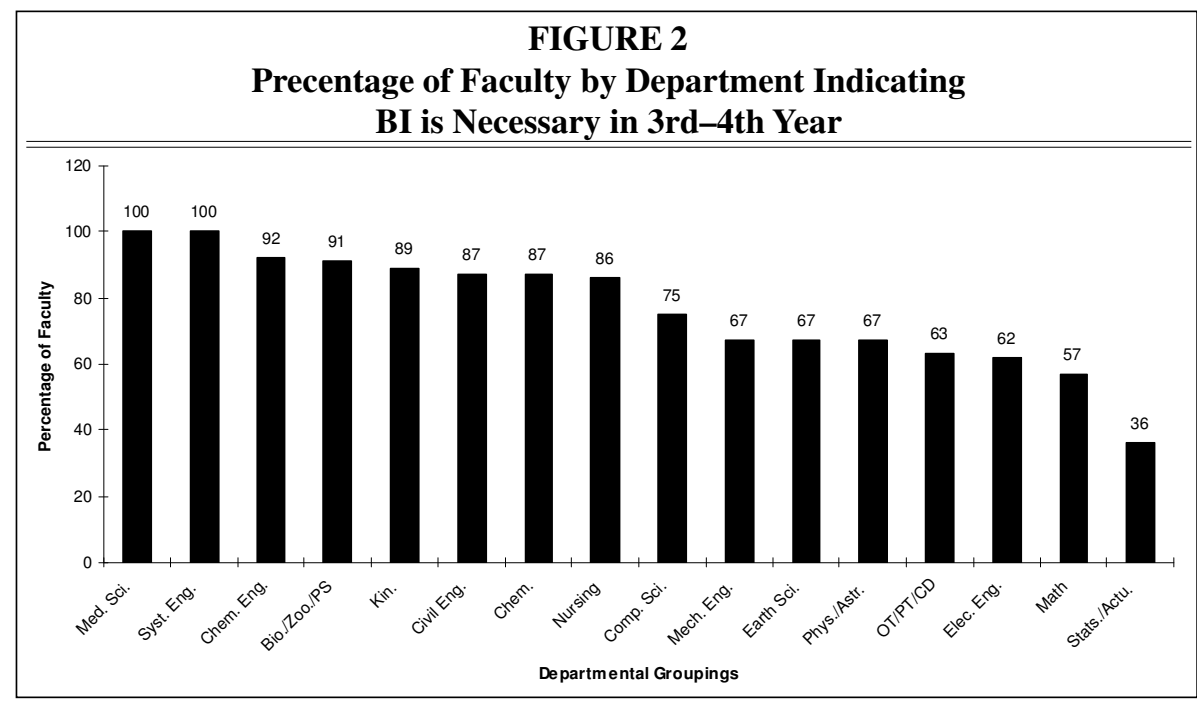

data analysis purposes and comparable to Cannon's response of 232 surveys. Thirty-eight faculty members (20 at Western and 18 at Waterloo) returned statement-of-interest cards.

Data from the returned questionnaires were entered into an SPSS for Windows data matrix, and analyzed during the winter and spring of 1997. During the summer and fall of 1997, 35 in-depth, tape-recorded interviews were conducted with volunteer faculty members at the two sites. Currently, transcription and analysis of the interviews are ongoing, using a qualitative data analysis software called The Ethnograph.

This article, therefore, reports primarily on the survey data, in comparison with Cannon's survey findings at York. However, preliminary observations from the in-depth interviews are included where appropriate. A more complete discussion of the interview portion of the research is forthcoming.

\section{Findings}

\section{Demographic Characteristics}

The majority of respondents were fulltime faculty $(89 \%)$, with six percent being sessional and five percent regular part-time. The distribution of teaching experience was fairly even: 23 percent had taught for seven years or less, 25 percent had taught between eight and fifteen years, 21 percent had taught between sixteen and twenty-five years, and 31 percent had taught for more than twenty-six years at the university level. Responses by faculty included 46 percent of respondents from the sciences, 30 percent from health sciences, and 23 percent from engineering. ${ }^{13}$

\section{Perceptions of Students' Library Research Skills}

As noted in the introduction, reliance on texts for the first one to two years of study in the sciences and engineering would suggest that perhaps students have less need to make use of the library and thus less need for BI early in their academic careers. When faculty members were asked whether they thought BI was necessary for their undergraduates, as anticipated, 78 percent thought it was necessary at the third- and fourth-year level, but a surprising 69 percent stated that it was also necessary at the first- and second-year level, a finding that directly contradicts much of the current thinking. It is evident that faculty in certain departments are more likely to see BI as being necessary in the first to second year (figure 1). For instance, 80 percent or more of the faculty in kinesiology, nursing, chemical engineering, medical sciences, sys- 


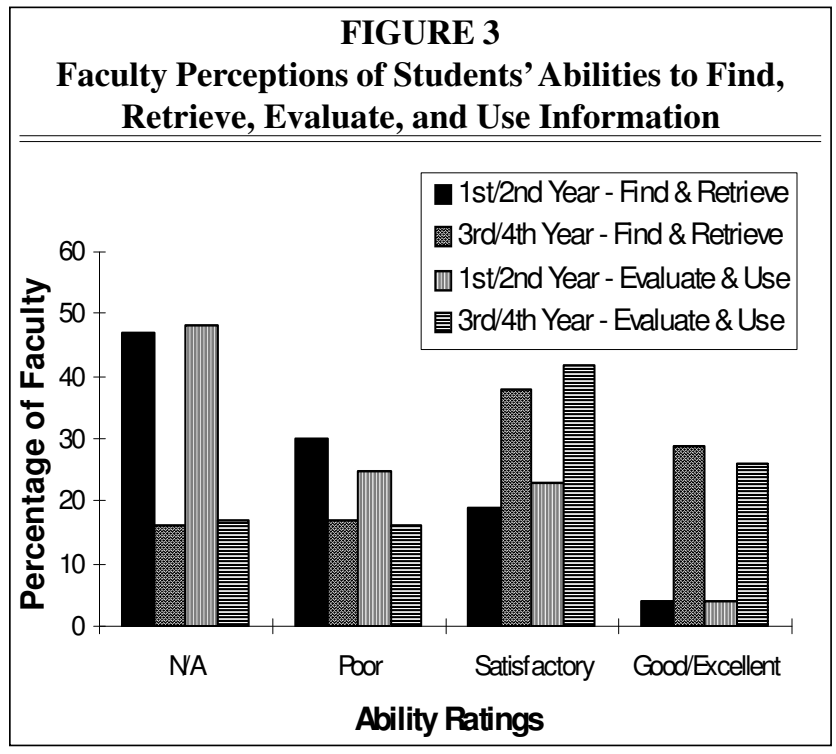

the comparable figures in the York study, there is no noticeable difference. In both studies, only a few departments indicated that information literacy skills are not very important for their students. In other words, faculty in the sciences and engineering were not more likely to think that library research skills are less important for their students.

Given that a majority of faculty thought that instruction in library research was necessary

tems engineering, and earth sciences indicated that BI is necessary, whereas faculty in computer science, mathematics, physics, and statistics indicated that it is not. In the third and fourth year (figure 2 ), this changes slightly, with medical sciences, systems engineering, chemical engineering, and biology faculty indicating the importance of BI in the upper years, whereas occupational/physical therapy, electrical engineering, mathematics, and statistics faculty indicate that it is not as important.

... another common faculty perception was that students who had not learned to do library-based research by their upper years were unmotivated, uninterested, or just poor students.

It is worth emphasizing here that although some departments indicated that library research instruction was not very important for their students regardless of level (such as mathematics, statistics, and physics), more than 60 percent of the faculty in a very large number of departments believed that library research instruction was important in the first to second year, third to fourth year, or both. In fact, when comparing figures 1 and 2 with even in the lower years, how did they rate their students' abilities to do library research? A 5-point scale of "not applicable," "poor," "satisfactory," "good," or "excellent" was used to assess this. For first- to second-year students, 48 percent of the faculty responded that library research was "not applicable," a figure that BI noted previously. In retrospect, it may be that many faculty did not know what their students' abilities were and so responded in the "not applicable" category. Nevertheless, 29 percent of the faculty rated their first- to second-year students' abilities as poor and 19 percent rated them as satisfactory.

The picture changes somewhat by the third and fourth years, with faculty rating their students' abilities to be satisfactory $(35 \%)$ to good $(26 \%)$, with only 17 percent rating them as poor. Faculty perceive, therefore, that students' abilities have improved considerably by their senior years, a result that is consistent with Cannon's findings for the arts/humanities and social sciences. As to how this improvement happens, interviews with faculty revealed that a very large number of faculty admit they have a poor understanding of how students learn to do library-based research. The most common seems to contradict the perceived need for 


\begin{tabular}{|c|c|c|c|}
\hline \multicolumn{4}{|c|}{$\begin{array}{c}\text { TABLE } 1 \\
\text { Proportion of Faculty Whose Courses } \\
\text { Require Library Research, By Year } \\
\end{array}$} \\
\hline & $\begin{array}{c}\text { No } \\
\text { Courses }\end{array}$ & $\begin{array}{c}\text { Some } \\
\text { Courses }\end{array}$ & $\begin{array}{c}\text { All } \\
\text { Courses } \\
\end{array}$ \\
\hline 1 st-2nd year & $59 \%$ & $30 \%$ & $12 \%$ \\
\hline 3 rd-4th year & 17 & 44 & 39 \\
\hline
\end{tabular}

thinking was that students somehow learned to do this on their own, by visiting libraries and using the resources available, or that they were approaching librarians, who then showed them the intricacies. These types of observations correspond to Hardesty's "resource" view of teaching-that if enough resources are amassed, students will learn through exposure. ${ }^{14}$ Related to this, another common faculty perception was that students who had not learned to do library-based research by their upper years were unmotivated, uninterested, or just poor students. Unfortunately, these views tend to perpetuate the type of individualistic trial-and-error learning environment that many faculty themselves experienced in graduate school but that does not develop the information literacy skills the majority of undergraduates today will need to be productive members of society. However, it also should be noted that a small number of faculty do have a good idea of what is required to improve students' library research skills, even if they themselves are not always acting on this knowledge.

Using the same 5-point scale, faculty members were then asked to rate their students' abilities to (1) find and retrieve information, and (2) evaluate and effectively use the information they obtain. Figure 3 shows a familiar trend: almost half the faculty perceive that finding, retrieving, evaluating, and using information is not applicable for first- and second-year students. Nevertheless, these students are perceived as much less able to find, retrieve, evaluate, and use information than students in their senior years. Interestingly, faculty members do not rate students' skills in finding/retrieving and evaluating/using information differently, also a finding noted by Cannon.

\section{Expectations regarding Student Assign- ments}

A large proportion of the respondents indicated that BI was necessary in the lower years, the upper years, or both. Two interpretations of this result could be that a large number of faculty either see the importance of library research skills in principle or already incorporate certain aspects of information literacy into their courses. If the latter, what are the specific requirements for undergraduates to do library research in their science and engineering courses? What are faculty expectations with respect to the quality of student assignments? To explore these issues, the survey included a number of questions about courses and expectations for student assignments.

On the other hand, 41 percent of respondents indicated that some or all of their courses in the first and second years required library research.

Faculty were asked how many of their courses required students to do library research (table 1). For first- and second-year students, the majority of faculty (59\%) indicated that none of their courses required library research. Subsequent interviews with faculty members revealed that this result reflected a number of factors, including: the heavy emphasis on textbooks in the lower years in many disciplines, a belief that there was so much essential material to cover that students could not be expected to do much beyond the textbook, a lack of TA support to facilitate library research assignments, the overall difficulty of planning library research for very large classes, and difficulty in motivating students in lower years to do anything beyond the textbook. On the other hand, 41 percent of respondents indicated that some or all of their courses in the first and second years required library re- 


\begin{tabular}{|c|c|}
\hline \multicolumn{2}{|c|}{$\begin{array}{c}\text { TABLE } 2 \\
\text { Types of Assignments Requiring } \\
\text { Library Use }\end{array}$} \\
\hline Types of Assignments & $\begin{array}{c}\text { Faculty } \\
\text { Assigning }\end{array}$ \\
\hline Short papers & $52 \%$ \\
\hline Research or design projects & 51 \\
\hline Long papers/essays & 39 \\
\hline Lab or tutorial reports & 37 \\
\hline Other & 18 \\
\hline
\end{tabular}

search. Departmental groupings in which at least half the faculty indicated that this was true included biology, physics/astronomy, nursing, medical sciences, kinesiology, occupational/physical therapy, and chemical engineering. Noticeably absent from this list are most of the engineering departments, mathematics, statistics, and computer science.

As anticipated, for third- and fourthyear courses, the proportion of faculty indicating that no library research was required in their courses fell noticeably to 17 percent. The vast majority of faculty $(83 \%)$ responded that some or all of their upper-level courses did require library research.

Faculty members were then asked what types of assignments requiring library research they routinely included in their courses. As table 2 shows, about half the faculty required either short papers or research/design projects in their courses, and slightly more than a third required longer papers or lab/ tutorial reports. Although comparable data are not available from Cannon's research, it seems reasonable that there would be a greater emphasis on research/design projects and lab reports in science, health sciences, and engineering, reflecting the applied or practical aspects of many disciplines within those faculties. It is encouraging to think, then, that the faculty are expecting students to do library research even in relation to those parts of their programs.

Faculty members were also asked what types of literature they expected students to use in doing assignments. Table 3 shows some interesting results. The overwhelming majority of faculty wanted students to use scholarly journals and monographs. Although this is perhaps to be expected, it still raises the issue of whether students know how to find the materials that faculty expect to see in their bibliographies. Somewhat more surprising is the expectation that undergraduates should be using review articles (67\%), which are rather specific types of articles that are not easily found unless one is already familiar with the purpose and occurrence of review articles. In relation to this, several of the faculty interviewed observed that students did not seem to understand what review articles were or how they should be using them, which is problematic if more than two-thirds of the faculty expect students to use them.

About half the faculty expected that students should be using the secondary literature in the form of electronic indexes and abstracts, which is surprisingly low given the emphasis on the scholarly journal literature. When combined with print indexes, the figure rises to 83 percent, but this may be misleading because the same faculty could have checked both categories. Nevertheless, this figure does suggest that there is still a large proportion of faculty who do not expect students to

\begin{tabular}{|lc|}
\hline \multicolumn{2}{|c|}{ TABLE 3 } \\
\multicolumn{1}{|c|}{$\begin{array}{c}\text { Types of Literature Faculty } \\
\text { Expect Students to Use }\end{array}$} \\
\hline \hline \multicolumn{1}{|c}{ Faculty } \\
Types of Literature & Expecting \\
\hline Scholarly journals & $90 \%$ \\
Monographs & 83 \\
Review articles & 67 \\
Electronic indexes/abstracts & 53 \\
Handbooks, manuals & 40 \\
Government documents & 32 \\
Print indexes/abstracts & 30 \\
Encyclopedias, dictionaries & 25 \\
Statistical data & 21 \\
Popular literature & 19 \\
\hline
\end{tabular}




\begin{tabular}{|lc|}
\hline \multicolumn{2}{|c|}{ TABLE 4 } \\
$\begin{array}{l}\text { Elements of Students' } \\
\text { phibs Examined by }\end{array}$ & Faculty \\
\hline \hline & $\begin{array}{c}\text { Faculty } \\
\text { phies Examing }\end{array}$ \\
\hline Types of Literature & Examining \\
Type of source & $80 \%$ \\
Breadth of coverage & 63 \\
Currency & 57 \\
Correct citation format & 55 \\
Expert authors & 44 \\
Other & 8 \\
\hline
\end{tabular}

use indexes and abstracts. This may be partially explained by the comments of numerous faculty interviewed (particularly in the sciences) who gave students key citations to assist them in starting to research their topics. Many faculty remarked that following a citation trail based on key authors was often preferable to doing a database search because students viewing a long list of citations often had no idea which authors were influential or important. However, this preference may be somewhat instructor specific because other faculty remarked that learning how to use bibliographic databases and sort through citation lists were important skills for students in their disciplines.

Faculty members have definite expectations about the kinds of literature students should be using. To determine how they assess whether students are meeting this expectation, faculty were asked about the aspects of students' bibliographies that they examine when grading assignments. From table 4, it is evident that faculty are looking primarily for specific types of sources and sources that provide sufficiently broad coverage of the topic. Currency of sources, correct citation formats, and inclu- sion of expert authors are less important but still are considered by about half the faculty.

\section{Pedagogical Practices}

To explore what faculty actually do in the classroom with respect to improving the information literacy of their students, the survey asked faculty to indicate the pedagogical practices used to prepare their students to do library-based research. Table 5 presents the results of this question. Half (or more) of the faculty responded that they never use assignments to introduce library research and never talk about retrieval tools, search strategies, or the Internet in class, whereas about a quarter of the faculty never discuss the research process in general, or appropriate indexes/abstracts. Although these results suggest that a large proportion of faculty are doing very little or nothing about information literacy in their classes, it is nonetheless encouraging that 30 to 50 percent of faculty are teaching various aspects of information literacy in their courses at least some, or all, of the time. This suggests that there is a reasonable base of faculty support upon which to build, by either assisting those faculty who already incorporate some aspects of information literacy in their courses to do a bit more or encouraging faculty to move out of the "never" category and into the "some" or "all" categories through the incorporation of aspects of information lit-

\section{TABLE 5}

\section{Faculty Pedagogical Practices for Introducing Library Research}

\begin{tabular}{|c|c|c|c|}
\hline & \multicolumn{3}{|c|}{ Percentage of Faculty Using } \\
\hline & Never & Sometimes & Always \\
\hline Assignment: library resources & $50 \%$ & $37 \%$ & $13 \%$ \\
\hline Assignment: critical thinking & 19 & 36 & 45 \\
\hline Explanation: research process & 26 & 52 & 22 \\
\hline $\begin{array}{l}\text { Explanation: retrieval tools } \\
\text { and search strategies }\end{array}$ & 53 & 42 & 5 \\
\hline Explanation: Internet & 65 & 30 & 5 \\
\hline $\begin{array}{l}\text { Explanation: indexes, } \\
\text { reference tools }\end{array}$ & 29 & 54 & 17 \\
\hline
\end{tabular}




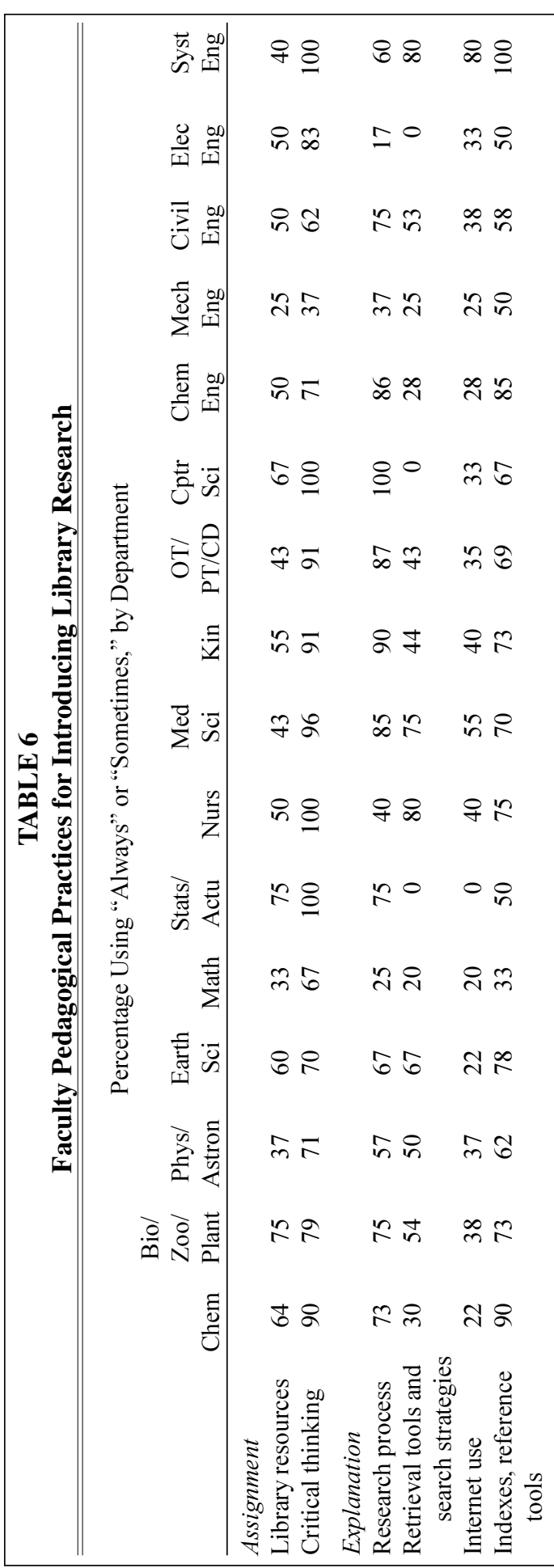

eracy into their courses. Also encouraging is the fact that 81 percent of faculty are attempting to craft assignments to foster students' critical thinking skills.

Pedagogical practices with respect to information literacy vary considerably from department to department, as table 6 demonstrates. Due to the low number of responses in some categories, differences may not be statistically significant but nevertheless may be indicators of some interesting trends. Scanning down the columns, it can be seen that:

- Proportionately more faculty in statistics/actuarial sciences and chemistry, and fewest in mathematics, give an assignment requiring students to use library resources.

- All the faculty who responded from computer science give explanations of the research process.

- Proportionately more faculty in systems engineering and medical sciences discuss the Internet.

- Proportionately more faculty in systems engineering and chemistry discuss specific indexes and reference tools, whereas no faculty in statistics or electrical engineering do this.

- The highest proportion of faculty using all six teaching practices is found in systems engineering and the lowest in mechanical engineering;

- Overall, the highest proportion of faculty usage of all six teaching practices is in the health sciences.

These results are comparable to Cannon's findings that different departments in arts/social sciences have preferred or habitual pedagogical approaches for information literacy. In her study, although assignments to require students to use the library were a common practice, some departments (such as philoso- 
phy) did far less of this than others (such as English).

Cannon's study also revealed some surprising challenges to conventional thinking. For instance, proportionately fewer faculty in political science and philosophy were incorporating information literacy components into their teaching than were faculty in the French department. One might have anticipated that, given the nature of those disciplines, the reverse finding would have been true. Similar challenges are seen in the authors' study. For example, statistics/actuarial sciences and computer science are commonly thought of as being less likely to require their students to use the library, even in the upper years, a perception confirmed through the interviews with faculty. Despite this, this study's results show that there are faculty in those disciplines designing assignments to encourage use of library resources and explaining the research process in class. It is also evident from the data that even divisions in the same discipline (such as engineering) can differ dramatically in the amount of information literacy incorporated into the curriculum. Chemical, civil, and systems engineering are doing more in this regard than mechanical and electrical engineering. Similar differences are noticeable across the range of disciplines in the sciences, with mathematics doing the least overall, a finding also true in Cannon's study.

Another perspective on pedagogical practice emerges when the rows across are scanned. It is apparent that:

- The majority of faculty in all departmental groupings except one are designing assignments to facilitate critical thinking skills.

- Explaining indexes and reference tools in class is the most common practice (the majority of faculty in 15 of the 16 groupings indicate that they do this).

- Explaining information retrieval options and search strategies is the most variable practice (the majority of faculty in only 7 of the 16 groupings indicate that they do this).
- Explanation of the Internet is the least likely practice (done by the majority of faculty in only two groupings).

These findings are especially interesting when compared to Cannon's data for the arts/social sciences. As in the authors' study, Cannon found that the most frequent practice was to design assignments to foster students' critical thinking skills. The second most common practice was to design assignments to introduce students to library resources or informationgathering in some way ( $78 \%$ of faculty). However, this practice does not appear to be as widespread in the sciences and engineering, where only 50 percent of faculty do this some or all of the time. On the other hand, a much higher proportion of the science and engineering faculty $(74 \%)$ provide an explanation of the research process in class than in the arts / social sciences (30\%). As well, a much higher proportion of the science and engineering faculty $(71 \%)$ explain specific indexes and reference tools than their arts / social science counterparts ( $28 \%)$. Furthermore, the authors' data also show that almost half $(47 \%)$ of the science/engineering faculty attempt to explain retrieval tools and search strategies in class some or all of the time, a question not asked by Cannon.

These findings are quite surprising and perhaps controversial, suggesting that it is a myth that arts and social sciences faculty will be more likely to incorporate information literacy components into their courses because of the intrinsic nature of those disciplines and how they are taught. True, the use of specific assignments to force students to use the library does seem to be a more common approach in the arts/social sciences. However, this study's results suggest that science and engineering faculty are more likely to incorporate explanations of specific sources, tools, and retrieval mechanisms into their classes. Two good examples of this would be chemistry (which must incorporate Chemical Abstracts and/or Beilstein into the curriculum) and civil engineering (which must incorporate particular handbooks of structural standards). 


\begin{tabular}{|lccc|}
\hline \multicolumn{4}{|c}{ TABLE 7 } \\
Faculty Use of Library Instructional Services \\
\hline \hline \multicolumn{4}{c}{ Percentage of Faculty Using } \\
& Never & Sometimes & Always \\
\hline Library tour by TA & $93 \%$ & $6 \%$ & $2 \%$ \\
General research class by TA & 91 & 7 & 2 \\
Library tour by library staff & 55 & 33 & 12 \\
General research class by librarian & 75 & 19 & 6 \\
Topic-specific class by librarian & 81 & 13 & 6 \\
Demo of resources by librarian & 63 & 28 & 9 \\
Hands-on workshop by librarian & 80 & 13 & 7 \\
\hline
\end{tabular}

an infrastructure problem: neither library has a computer lab for teaching, with appropriate site licences for demonstrating various resources. ${ }^{15}$ Although librarians could arrange to use generalpurpose campus labs, this complicates delivery considerably for both the faculty member and the librarian,

\section{Use of Library Instructional Services and Librarians}

The university library systems at the two universities offer a range of active instructional services to the sciences and engineering faculties, including in-class lectures and demonstrations, workshops on specific resources (such as OVID, Biological Abstracts), tours, and general assistance in designing appropriate librarybased assignments. A number of survey questions were included to determine how much use faculty members make of available services and to explore reasons for not making use of them.

Table 7 demonstrates that a high proportion of faculty have never made use of library instructional services, despite the fact that both library systems make efforts to publicize these services. The most heavily used services were general library tours (by almost half of faculty) and demonstrations by librarians (by over one third of faculty). Each of the other services had been used by less than a quarter of the faculty, with topic-specific classes and hands-on workshops given by librarians used the least. Why? The low use of topic-specific classes may result from a lack of awareness of both the service and what librarians are willing to do. Many of the faculty interviewed commented that they had not thought of having librarians participate in their courses in this way and had not realized that librarians would be willing to develop topic-specific classes for them. The low use of hands-on workshops may reflect thus making this a less attractive option.

With respect to the role of TAs in library research instruction, the data report that a very small proportion of faculty in sciences and engineering use TAs to either take students on library tours or teach library-based research skills in tutorials. Thus, the idea that librarians should concentrate on teaching TAs, who will then teach undergraduates, should be examined very critically. Overall, concentrating instructional efforts on TAs as a way to reach undergraduates does not seem to be a good strategy, except possibly with certain departments that are known to use this approach.

Table 8 indicates responses to the instructional services question by departmental grouping. Scanning down the columns, it is evident that:

- Certain departments, such as nursing and kinesiology, do use TAs to assist with information literacy in their courses.

- Faculty in nursing, earth sciences, and chemistry made the most use of library tours.

- Proportionately more faculty in nursing, biology, and earth sciences had a librarian give a class on library research in general.

- Proportionately more faculty in systems engineering, nursing, and biology had a librarian give a topic-specific class.

- Proportionately more faculty in nursing and earth sciences had a librarian give a demonstration of library resources. 


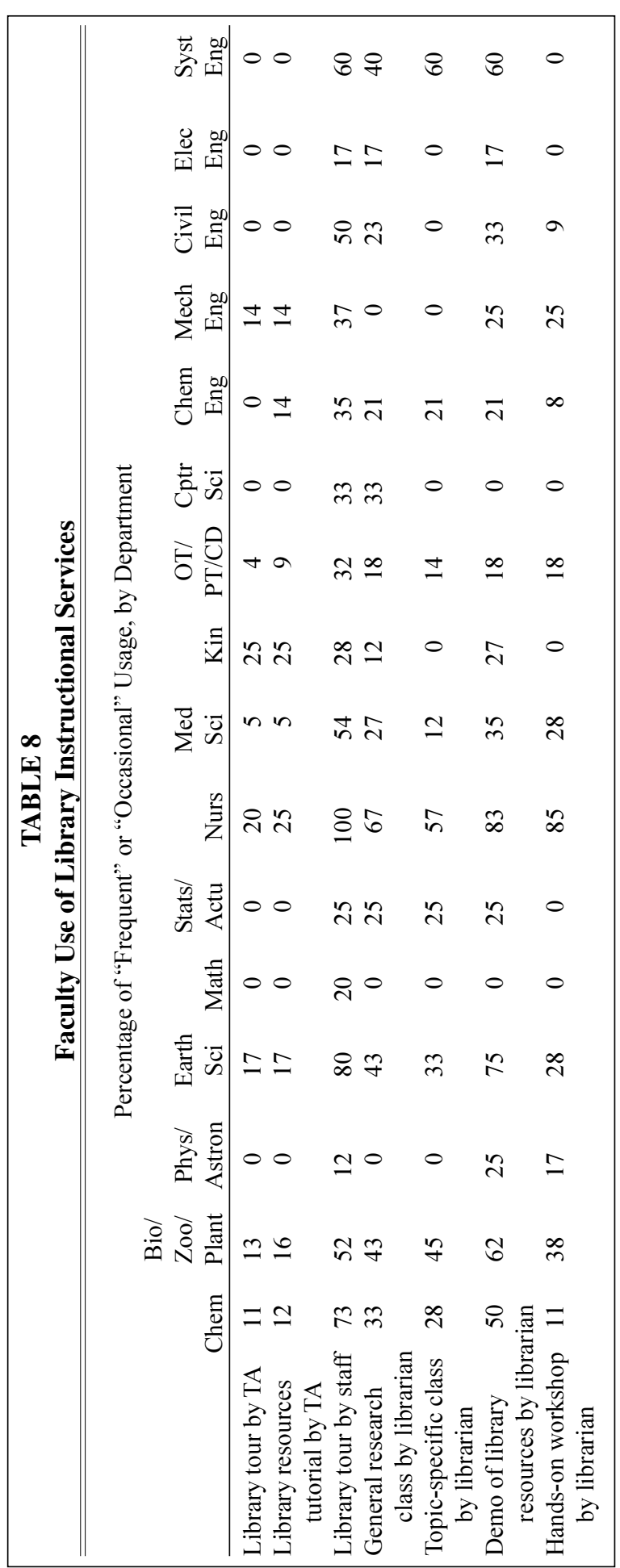

- Hands-on workshops by librarians were not used very much except in nursing.

- Nursing made the heaviest use of all six instructional services, and mathematics made the least.

In addition to what can be ascertained from the columns, scanning across the rows reveals that:

- All departmental groupings make use of library tours given by library staff to some extent.

- Far less than half of the faculty have had a librarian give a general research class, and a much lower proportion has had a librarian give a subjectspecific class.

- Demonstration of library resources by a librarian is the most variable category, with some departments using this service a lot and others using it relatively little.

- Hands-on workshops are not well used by any department except nursing.

The findings in table 8 are quite analogous to those in Cannon's study, where particular departments made use of instructional services to varying degrees. For instance, Cannon found that sociology faculty made the greatest use of library tours, whereas English faculty were more likely to have a librarian give a subject-specific class. Another comparable finding was that pedagogical practices centered on the librarian were used by lower proportions of faculty than those the faculty can do themselves. In other words, if faculty are doing anything about information literacy, they are doing it with little input from librarians. Although this is noticeably true in both studies, it 
should be pointed out that a comparison of this study's data (tables 5 and 7) with the comparable data in Cannon's study reveals that faculty in the sciences and engineering actually made greater use of library instructional services than did the arts/social sciences faculty in the York sample.

When faculty who did not make use of library instructional services were asked for their reasons, most said that it was simply because such services were not necessary in their courses, echoing the observation from figures 1 and 2 that some faculty in science and engineering simply do not require extensive library research in their courses and thus do not see its importance. This finding is quite unlike the response from arts/social science faculty, where only nine percent gave this as the reason for not using instruc-

\section{... a fairly large proportion of faculty $(39 \%)$ would prefer that librarians assume primary responsi- bility for information literacy.}

tional services. In other words, a much higher proportion of arts/social science faculty perceive that library research instruction is important for their courses, even though they still may not be making use of it (for different reasons).

A quarter of the faculty in both perceive difficulty scheduling library instructional services into their courses $(24 \%$ in this study, 26\% in Cannon's). From the interviews for this study, science and engineering faculty perceive that the disciplinary knowledge they are required to cover in their courses is already too large, leaving very little room for "frills" such as writing, communication, and information literacy skills. There was also a noticeable resentment on the part of some faculty at having students who had not been adequately educated in these areas in high school. Although librarians cannot directly address the issue of the everexpanding knowledge base of the disciplines, they can stress to faculty that information literacy is not a frill but, rather, an essential component of scholarly work in any discipline.

On the other hand, librarians can do something about the lack of awareness of library instructional services $(31 \%$ in this study, $40 \%$ in Cannon's), a persistent barrier no matter what the discipline. Interviews with faculty members further revealed that although many of were somewhat aware that librarians would come into their classes, they were not aware of what librarians could actually do for them in this regard or had never thought about making use of librarians in this way until the possibility was suggested to them through the interview process. These observations suggest that more direct, interpersonal outreach by librarians is needed if faculty are to be made aware of the instructional services that librarians can provide; obviously, campuswide advertising alone does not make this very apparent.

On the bright side, it is heartening to note that faculty in science and engineering do not question the academic abilities of librarians: only six percent indicated that they thought librarians were not knowledgeable enough about the discipline in question to provide instructional services for their course(s). Furthermore, faculty are not particularly concerned about sharing the classroom with librarians because only four percent indicated that they preferred to "do it myself."

When asked who should provide library research instruction, 46 percent of faculty responded that, as in Cannon's study, they were open to a collaborative approach to teaching information literacy. In this study, chemistry, nursing, kinesiology, electrical engineering, and systems engineering favored a collaborative approach. Nevertheless, a fairly large proportion of faculty (39\%) would prefer that librarians assume primary responsibility for information literacy. Departments in which a majority of faculty indicated this preference were medical sciences, occupational and physical therapy, chemical engineering, and mechanical engineer- 
ing. Therefore, the data suggest that across all the disciplines of the arts, social sciences, sciences, and engineering, librarians must be open to a variety of approaches in teaching information literacy, in some cases operating collaboratively and in other cases taking sole responsibility. A single pedagogical approach will not meet the needs of a substantial portion of the disciplines involved.

\section{Usefulness of Library Instruction}

To gauge the usefulness of library instruction, faculty who had had a librarian give some form of library instruction in the past were asked to answer questions about the experience. Seventy-eight faculty (33\% of the sample) responded, which is noticeably lower than Cannon's response rate of 44 percent for the same questions. In other words, proportionately fewer faculty members in this study have had a librarian give in-class instruction than in the arts/social sciences study.

Faculty were asked if they had ever discussed the content or collaborated on developing exercises with the librarian prior to the instructional session. Their responses were fairly evenly distributed, with 53 percent stating they had collaborated and 47 percent indicating they had not. This distribution seems to parallel the finding noted previously that some faculty prefer a more collaborative approach and others prefer that the librarian assume responsibility for the instruction. Faculty were then asked if they had attended the instructional session(s) in question. Slightly more than half (56\%) said they had.

Faculty were also asked about the usefulness of the instruction for their students and evidence from students' assignments of greater library use. The response to the usefulness question was positive (77\%), with 21 percent unsure as to how useful it was. Although this is a more cautious endorsement than in Cannon's study ( $96 \%$ positive), these data may be a more realistic reflection of faculty perception because Cannon's survey did not have a category for "unsure." With respect to evidence from students' assignments, 57 percent of faculty responding thought that assignments did show greater use of library resources, but 39 percent were unsure. Only four percent did not see any evidence of improvement after the instructional session. Finally, faculty were asked if they had given the librarian any feedback after the instructional session(s), with 56 percent replying yes and 44 percent replying no.

Overall, it seems that faculty who have had a librarian give an instructional session were pleased with the result for their courses and did see evidence of improvement in students' library research skills in their assignments. However, it is also clear that some faculty are not sure what should be in library instructional sessions and also are unsure how to judge whether students' library research skills have actually improved as a result. This may be partially explained by the fact that 44 percent of faculty did not attend the instructional sessions and thus were unsure what had been covered and how to judge possible student improvement. Furthermore, because just more than half the faculty discussed the session afterward with the librarian, it does seem that there is room for improvement in this regard as well. Faculty and librarians obviously need to discuss the learning objectives and desired outcomes for instructional sessions so that both parties have a clearer idea of what is to be achieved and how these achievements can be evaluated by professors.

\section{Faculty Interest in BI Options}

The final series of questions on the survey explored faculty interest in a number of options for the delivery of bibliographic instruction. Faculty were asked to indicate support for options relating to the development of their own information literacy, instructional services for their courses, and other assistance using a 5-point scale from 4 (strong interest, would support) to 1 (no opinion, or not applicable). Tables 9 and 10 show the re- 


\begin{tabular}{|c|c|c|c|c|}
\hline \multicolumn{5}{|c|}{$\begin{array}{c}\text { TABLE } 9 \\
\text { Faculty Interest in Library Instruction Options } \\
\text { for Faculty and Courses }\end{array}$} \\
\hline \multicolumn{5}{|c|}{ Percentage of Faculty "Interested" or "Strongly Interested" } \\
\hline For Faculty & & & & \\
\hline Review of research tools/techniques & $67 \%$ & $63 \%$ & $65 \%$ & $73 \%$ \\
\hline Hands-on workshops on specific tools & 69 & 61 & 73 & 79 \\
\hline $\begin{array}{l}\text { For Courses } \\
\text { In-class course-specific lecture by librarian }\end{array}$ & 50 & 40 & 58 & 61 \\
\hline In-class demo of resources by librarian & 50 & 42 & 54 & 58 \\
\hline $\begin{array}{l}\text { Library research assignment designed by } \\
\text { faculty with librarian }\end{array}$ & 33 & 29 & 33 & 40 \\
\hline Team teaching/grading with librarian & 23 & 18 & 29 & 25 \\
\hline
\end{tabular}

sponses of faculty indicating a 4 (strongly interested) or a 3 (interested) for the suggested options.

As table 9 indicates, options that related to faculty members' own information literacy were by far the most popular. In particular, there was considerable faculty interest in more hands-on workshops of specific tools, with a high of 79 percent of faculty in the health sciences supporting this option.

Faculty support of instructional services involving librarians was less positive, with only about half supporting inclass lectures or demonstrations by librarians. Faculty in the sciences were generally less interested in this than faculty in engineering and health sciences. To determine which departmental groupings supported these two options, a crosstabulation was carried out. Departments in which a majority of faculty supported the idea of in-class course- specific lectures included chemistry, biology, nursing, medicine, occupational and physical therapy, and chemical engineering. Surprisingly, only two groupings clearly indicated no interest in in-class lectures: physics/astronomy and earth sciences. For in-class demonstrations by librarians, support was indicated by a majority in chemistry, biology, nursing, kinesiology, occupational and physical therapy, chemical engineering, civil engineering, and systems engineering. For this option, only earth sciences faculty were clearly not interested.

Despite the 46 percent interest in a collaborative approach to teaching information literacy shown on an earlier question, only about a third of faculty were interested in collaboratively designing assignments and an even smaller proportion were interested in team teaching or grading. Departments in which a third or more of the faculty supported the collaborative design of assignments and/or team teaching/grading included a now familiar group: chemistry, biology, nursing, medical sciences, kinesiology, occupational and physical therapy, and chemical engineering. Because it seems that for many faculty, notions of collaboration do not extend to assignments, teaching, or grading, the question then arises as to what the faculty conception of collaboration really is. Perhaps faculty and librarians have quite different interpretations of what it means to deliver information literacy in a collaborative fashion, which is an issue that could be explored in further research.

It is clear from table 10 that there was interest in more "how-to" guides, a finding that goes along with the faculty interest in more hands-on workshops. Support for traditional subject bibliographies is lower, except in health sciences. This 


\begin{tabular}{|c|c|c|c|c|}
\hline Faculty Interest in Oth & $\begin{array}{l}\text { ABLE } 1 \\
\text { ar Libra }\end{array}$ & ry Instr & ction $\mathrm{O}$ & ptions \\
\hline Percentage of Faculty "In & $\begin{array}{l}\text { terested" } \\
\text { Overall }\end{array}$ & $\begin{array}{l}\text { or "Stron } \\
\text { Science }\end{array}$ & $\begin{array}{l}\text { ly Interes } \\
\text { English }\end{array}$ & $\begin{array}{l}\text { ted" } \\
\text { Health }\end{array}$ \\
\hline $\begin{array}{l}\text { More subject guides, } \\
\text { bibliographies }\end{array}$ & $35 \%$ & $27 \%$ & $36 \%$ & $46 \%$ \\
\hline More how-to guides & 48 & 42 & 48 & 58 \\
\hline $\begin{array}{l}\text { Required library research } \\
\text { component, 1st year }\end{array}$ & 38 & 16 & 42 & 54 \\
\hline $\begin{array}{l}\text { Required library research } \\
\text { component, upper years }\end{array}$ & 42 & 36 & 38 & 55 \\
\hline Optional credit course in & & & & \\
\hline 1 st year & 25 & 20 & 23 & 33 \\
\hline 2nd year & 25 & 24 & 24 & 28 \\
\hline 3 rd year & 23 & 29 & 19 & 18 \\
\hline 4 th year & 25 & 32 & 23 & 15 \\
\hline Required credit course in & & & & \\
\hline 1st year & 9 & 9 & 3 & 15 \\
\hline 2nd year & 9 & 10 & 12 & 6 \\
\hline 3 rd year & 13 & 13 & 12 & 13 \\
\hline 4 th year & 13 & 13 & 17 & 9 \\
\hline
\end{tabular}

course. This is an interesting finding given that many institutions recently have been moving in a formal way toward this model, with an institutional commitment to incorporating information literacy into all programs. ${ }^{16} \mathrm{Al}$ though there was some support from health sciences for a required library research component for first-year courses, engineering and science faculty were not as keen on this idea. Support was greatest for having a required library research module for upper-level courses. Furthermore, the proportion of fac-

result would suggest that librarians' attempts to facilitate individualized learning through informal BI methodologies such as help sheets and electronic help sources are in the right direction, and that faculty perceive that aids facilitating selfsufficient learning are good, for both themselves and their students.

Finally, table 10 also provides information on the interest in having required library research components at various levels and credit courses in library research. The least popular alternative was the library research methods credit course. Less than one quarter of the faculty were interested in such a course, whether optional or required (with the exception of health sciences, which slightly favored an optional credit course in the first year). Generally, the figures showing faculty interest in credit courses are far lower than in Cannon's study, perhaps suggesting that arts/social sciences faculty are more open to this approach than are faculty in the sciences and engineering.

The idea of a library research module or component for existing courses was far more popular than the idea of an entire ulty interested in the library research module approach was very close to the one favoring this approach in Cannon's study. It would seem, then, that faculty across a wide variety of disciplines are quite interested in seeing whether a library research component could be integrated into the courses in their specialities. Faculty in arts and social sciences are more interested in seeing this done at the first-year level, whereas faculty in the sciences and engineering are more supportive of this approach for upper-level courses.

\section{Discussion}

When compared to Cannon's study of arts/humanities and social science faculty, many of the findings in this study were quite similar. In this study's research, faculty generally thought their undergraduate students' skills in finding, retrieving, using, and evaluating information were poor in the lower years, but improved somewhat by the upper years. Along these lines, a large majority of faculty indicated that library research instruction for their students was important. However, the optimal timing of such 
instruction varied considerably by discipline. Faculty in some disciplines (such as nursing) wanted to have library instruction at the first- and second-year levels, whereas others (such as systems engineering) preferred library instruction for third- and fourth-year courses (although a few disciplines felt it was not important at any level). As well, more than half the faculty expected students to use the library for their assignments, even if these assignments took the form of lab reports or design projects. All of these findings have close parallels in Cannon's results.

\section{The idea of a library research module or component for existing courses was far more popular than the idea of an entire course.}

As in Cannon's study, a noticeable proportion of faculty were attempting to incorporate information literacy into their courses at least some of the time. In the arts/social sciences, these faculty members preferred to design assignments that required library usage, whereas in the sciences and engineering, they were more likely to talk about appropriate references tools and indexes in class. Unfortunately, in both studies, a large group of faculty did very little with respect to library research instruction in their own courses and were generally unaware that librarians would come into class to assist them in this regard. Joy Thomas also found this to be true in a study that looked at faculty attitudes toward library instruction at California State University in Long Beach in 1982 and again in 1990. She concluded that "most CSULB faculty still seem to feel little responsibility for assuring that their students develop library skills, traditional or electronic."17 It is somewhat surprising, then, that both this study and Cannon's found that about half of the faculty favored a more collaborative approach to library research instruction, involving both the librarian and the faculty member. The flip side of this finding, however, is that about half of the faculty did not favor a collaborative ap- proach and would like librarians to take sole responsibility for information literacy instruction.

What can be made of such findings, particularly as some of them appear to be so contradictory? As Maynard suggests, is it simply that faculty attitudes and practices with respect to BI are highly variable and inconsistent, defying any attempts to make sense of them ${ }^{18}$ The authors think not. There is now considerable evidence from this and other research that faculty attitudes toward information literacy are fairly consistent: faculty generally believe that students ought to know how to do library-based research and that the development of such skills is an important part of their education (except in a very small number of disciplines). The authors contend that the apparent inconsistency is not so much with faculty attitudes as with faculty pedagogical practices. Although some faculty have already made use of library instructional services, incorporating information literacy into their courses and making it a priority in their teaching, others have not. The question is, why not?

Interviews with faculty have been extremely helpful in revealing the factors involved in the "why not" of the information literacy equation. Whether or not an individual faculty member will become more proactive in integrating information literacy into his or her courses depends on the interplay among a number of complex variables that drive the educational process. Examples of the variables that may have an impact on individual faculty members include:

- discipline and disciplinary curriculum;

- program type (expectations, size, etc.);

- program pedagogical philosophy;

- class size;

- level of classroom support (TAs, etc.);

- failure of secondary education to adequately prepare students;

- personal philosophy of teaching and higher education; 
- personal skill with information retrieval;

- years of teaching;

- personal experiences learning to do library research;

- views of librarians' roles and services.

More of these factors may come into play for some faculty members than for others. Taking program pedagogical philosophy as an example, some programs incorporate aspects of information literacy directly into the curriculum, such as with a problem-based learning approach. Faculty who teach within such a curriculum structure are more likely to integrate information literacy into their courses because it is an integral part of the overall program philosophy and is not left up to individual faculty members. On the other hand, a factor such as disciplinary curriculum may negatively influence the incorporation of information literacy into courses. As noted by Thomas, a far higher proportion of faculty in her 1990 survey complained that the disciplinary curriculum was too full to incorporate information literacy than had been the case in $1982 .{ }^{19}$ The interviews for this study revealed that many faculty members hold the same belief.

\section{Conclusions}

Despite the complexity of the information literacy equation, certain general recommendations can be drawn from this research. First, although this has been stated many times before by other authors, the timing and tailoring of library instruction is critical. The study results show very clearly that a library research instructional program will not succeed if it is kept generic. Librarians involved in instructional activities must come to know individual disciplines, departments, and programs because all have slightly different expectations and needs. Instruction must be strongly course related.

Second, librarians must be prepared to take a flexible pedagogical approach. Some faculty are keen to have a collaborative experience, others are not. Librar- ians should not think that all instructional activities must take place in the same way or the needs of their faculty clients will not be met.

Third, the authors strongly concur with Cannon that more direct liaison with departments and individual faculty members must take place. Obviously, general advertising attempts to inform faculty about the expertise of librarians and the instructional services of the library have not worked terribly well. A more proactive and interpersonal marketing strategy is needed, with both departments and individual faculty members.

Fourth, hands-on review sessions and workshops for faculty should be a priority in the library instructional program. There appears to be considerable faculty interest in upgrading their own information literacy and some evidence to suggest that faculty who are more comfortable with information retrieval will be more likely to consider it for their own courses. However, setting such a priority will mean that two other barriers will have to be dealt with: (1) securing appropriate computer-equipped teaching labs for library use, whether within the library itself or elsewhere on campus; and (2) arranging for appropriate site licenses so that meaningful hands-on experiences can take place. Having these resources in place will make it considerably easier to deliver hands-on instruction to students as well.

Fifth, Cannon's suggestion to concentrate on making the user self-sufficient was reinforced in this study. The study results and interviews suggest that many faculty want to find information for themselves and also expect this of their students. To this end, faculty perceive that more self-directed learning is useful, for both themselves and their students, suggesting that more how-to guides, electronic help screens for various resources, and print and online pathfinders are desirable. However, faculty perceptions of what is best for their students and what students actually make use may be two different things, so librarians also must 
assess student use of such resources before committing large amounts of time to this endeavor. There is less interest in the development of comprehensive bibliographies, so librarians should not expend a lot of effort on such resources unless departments have indicated they will use them.

Finally, the Internet may provide academic librarians with a very useful way into campus classrooms. The survey results show that, compared to other resources, the Internet is the least likely to be discussed in class by faculty, yet the study interviews revealed that faculty are very concerned about how students are using the Internet and whether it should be sanctioned. Some departments have banned the use of Internet resources for any of their courses. Clearly, faculty could use some assistance in deciding how to handle the growing demand from undergraduates to allow them to use the Internet. This is an area where academic librarians could become very actively involved and could put their expertise to effective use, while also creating opportunities for future valuable contributions to the life of the academy.

This research was supported by the Carroll Preston Baber Research Grant of the American Library Association. The authors express special thanks to their excellent research assistant, Lisa Given, and to Jennifer Noon of the Taylor Science \& Engineering Library, University of Western Ontario.

\section{Notes}

1. Lilith R. Kunkel, Susan M. Weaver, and Kim N. Cook, “What Do They Know? An Assessment of Undergraduate Library Skills," Journal of Academic Librarianship 22 (Nov. 1996): 430-34; Sonia Bodi, "Scholarship or Propaganda: How Can Librarians Help Undergraduates Tell the Difference?" Journal of Academic Librarianship 21 (Jan. 1995): 21-26; Patricia Wallace, "How Do Patrons Search the Online Catalog When No-one's Looking?" RQ 33 (winter 1993): 239-52; Lawrence Reed, "Locally Loaded Databases and Undergraduate Bibliographic Instruction," $R Q$ 33 (winter 1993): 266-73; Stan Nash and M.C. Wilson, "Value-added Bibliographic Instruction: Teaching Students to Find the Right Citations," Reference Services Review 19 (spring 1991): 87-92; Gillian Allen, "Database Selection by Patrons Using CD-ROM," College E Research Libraries 51 (Jan. 1990): 69-75.

2. Mark Rosenzweig and Graeme Gardner, "ChEs See Significant Gains and Changes," Chemical Engineering Progress (Nov. 1994): 54-61.

3. Julia Bichteler and D. Ward, "Information-seeking Behaviour of Geoscientists," Special Libraries 80, no. 3 (summer 1989): 169-78.

4. The terminology used to describe librarians' teaching activities with respect to information literacy varies greatly. Although some recent authors use the term information literacy quite freely, the more established term is bibliographic instruction, or BI. In this article, the terms BI, information literacy, and library research instruction are used interchangeably to describe librarians' efforts to teach students how to find, retrieve, critically evaluate and use appropriate information in all its forms.

5. J. Edmund Maynard, "A Case Study of Faculty Attitudes toward Library Instruction: the Citadel Experience," Reference Services Review 18 (summer 1990): 67-76.

6. Larry Hardesty, Faculty and the Library: The Undergraduate Experience (Norwood, N.J.: Ablex, 1991); see also Larry Hardesty, "Faculty Culture and Bibliographic Instruction: An Exploratory Analysis," Library Trends 44 (fall 1995): 339-67.

7. Ibid.

8. Robert Ivey, "Teaching Faculty Perceptions of Academic Librarians at Memphis State University," College E Research Libraries 55 (Jan. 1994): 69-82; Jean Major, "Mature Librarians and the University Faculty: Factors Contributing to Librarians' Acceptance as Colleagues," College $\mathcal{E}$ Research Libraries 54 (Nov. 1993): 463-9; Anne Lipow, “Outreach to Faculty: Why and How," in Working with Faculty in the New Electronic Library (Ann Arbor, Mich.: Pierian Pr., 1992), 7-24; G. Divay, A.M. Ducas, and N. Michaud-Oystryk, "Faculty Perceptions of Librarians at the University of Manitoba," College \& Research Libraries 48 (Jan. 1987): 49-62. 524-41.

9. Anita Cannon, "Faculty Survey on Library Research Instruction," $R Q 33$ (summer 1994): 
10. Janice Kelland, Bibliographic Instruction Programs in the Sciences. London, Ont.: Univ. of Western Ontario, Graduate School of Library and Information Science, 1995, Unpublished independent study.

11. For the sake of brevity throughout the discussion, the term sciences also will include the health sciences.

12. Cannon, "Faculty Survey on Library Research Instruction," 538.

13. Because departmental names and disciplinary orientations varied slightly between the two sites, departments were grouped if necessary. The departments or groupings for each area are as follows: Science includes chemistry, biology/zoology/plant sciences, physics/astronomy, earth sciences, computer science, mathematics/applied mathematics, and statistics/actuarial science. Engineering includes chemical, mechanical, civil/materials, electrical, and systems engineering. Health science includes nursing, kinesiology, occupational/physical therapy and communicative disorders, and medical sciences (i.e., medical science courses such as anatomy, immunology, neurology, biophysics, biochemistry, physiology, and pharmacology available to science undergraduates. The Faculty of Medicine per se is not included in the study.).

14. Hardesty, Faculty and the Library, 103.

15. Since the time of the study, the University of Western Ontario Library System has constructed a computerized instructional laboratory in the Weldon Library.

16. Two examples include Gabriela Sonntag and Donna Ohr, "The Development of a LowerDivision, General Education, Course-Integrated Information Literacy Program," College $\mathcal{E}$ Research Libraries 57 (July 1996): 331-38; Steve Gowler, "The Habit of Seeking: Liberal Education and the Library at Berea College," Library Trends 44 (fall 1995): 387-99.

17. Joy Thomas, "Faculty Attitudes and Habits concerning Library Instruction: How Much Has Changed Since 1982?" Research Strategies 12 (fall 1994): 209-23.

18. Maynard, "A Case Study of Faculty Attitudes toward Library Instruction."

19. Thomas,"Faculty Attitudes and Habits concerning Library Instruction," 217 